\title{
A Polymorphism in the Cyclooxygenase 2 Gene as an Inherited Protective Factor Against Myocardial Infarction and Stroke
}

Francesco Cipollone, MD

Elena Toniato, $\mathrm{PhD}$

Stefano Martinotti, MD

Maria Fazia, PhD

Annalisa Iezzi, MD

Chiara Cuccurullo, MD

Barbara Pini, MD

Sebastiano Ursi, PhD

Gianfranco Vitullo, MD

Maurizio Averna, MD

Marcello Arca, MD

Anna Montali, BS

Filomena Campagna, PhD

Sante Ucchino, MD

Francesco Spigonardo, MD

Stefano Taddei, MD

Agostino Virdis, MD

Giovanni Ciabattoni, MD

Alberto Notarbartolo, MD

Franco Cuccurullo, MD

Andrea Mezzetti, MD

for the Identification of New

Elements of Plaque Stability (INES)

Study Group

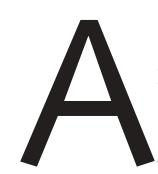

LTHOUGH MYOCARDIAL INfarction (MI) and atherothrombotic ischemic stroke are thought to be caused by rupture of vulnerable atherosclerotic plaques, ${ }^{1}$ they are recognized to be complex disorders that likely result from multifaceted interactions between an in-

Context Myocardial infarction (MI) and ischemic stroke are thought to be caused by matrix digestion by metalloproteinases (MMPs) leading to rupture of atherosclerotic plaques. Production of macrophage MMP-2 and MMP-9 is induced by cyclooxygenase $2(\mathrm{COX}-2)$ and prostaglandin $\mathrm{E}_{2}$ synthesis. Although COX-2 expression may be genetically determined, the relation between COX-2 polymorphisms and the risk of $\mathrm{MI}$ and stroke is unclear.

Objective To investigate the relationship between the $-765 \mathrm{G} \rightarrow C$ polymorphism of the COX-2 gene and clinically evident plaque rupture.

Design, Setting, and Participants Prospective, matched case-control study conducted between March 2002 and October 2003 among 864 patients with first MI or atherothrombotic ischemic stroke and 864 hospitalized controls. The groups were matched for age, sex, body mass index, smoking, hypertension, hypercholesterolemia, and diabetes. The $-765 \mathrm{G} \rightarrow \mathrm{C}$ variant of the COX-2 gene was genotyped by restriction endonuclease digestion of polymerase chain reaction products.

Main Outcome Measures Presence of the $-765 \mathrm{G} \rightarrow \mathrm{C}$ polymorphism of the COX-2 gene; COX-2, MMP-2, and MMP-9 expression and activity in plaques and in peripheral monocytes; urinary 6-keto $\mathrm{PGF}_{1 \alpha}$ (marker of endothelial prostacyclin); and endothelium-dependent and -independent forearm blood flow vasodilation.

Results The prevalence of $-765 \mathrm{GC}$ was 2.41 times higher among controls than among cases $(43.3 \%$ vs $17.9 \% ; P<.001)$. The prevalence of $-765 C \mathrm{C}$ homozygosity was 5.81 times higher $(6.4 \%$ vs $1.1 \% ; P=.04)$. Among participants carrying the $-765 \mathrm{CC}$ and $-765 \mathrm{CC}$ genotypes, the prevalence ratios for $\mathrm{MI}$ or stroke were 0.48 $(95 \% \mathrm{Cl}, 0.36-0.68)$ and $0.33(95 \% \mathrm{Cl}, 0.24-0.55)$, respectively. Expression of COX-2 and MMPs was significantly lower in atherosclerotic plaques from participants carrying the $-765 \mathrm{C}$ allele, while the $-765 \mathrm{G} \rightarrow \mathrm{C}$ polymorphism did not affect endothelial prostacyclin biosynthesis or endothelium-dependent vasodilation in vivo. In subgroup analyses ( $n=224$ cases), serum high-sensitivity C-reactive protein was significantly lower in patients carrying the $-765 \mathrm{C}$ allele (mean [SD], 0.78 [0.1] vs $2.56[0.4] \mathrm{mg} / \mathrm{L} ; P=.04$ ).

Conclusions We found that the $-765 \mathrm{G} \rightarrow \mathrm{C}$ polymorphism of the COX-2 gene is associated with a decreased risk of $\mathrm{MI}$ and stroke. Detection of this genotype may be useful for predicting genetic risk of $\mathrm{MI}$ and stroke.

JAMA. 2004:291:2221-2228

www.jama.com

Author Affiliations: G. d'Annunzio University of Chieti and G. d'Annunzio University Foundation, Chieti, Italy (Drs Cipollone, Toniato, Martinotti, Fazia, Iezzi, C. Cuccurullo, Pini, Ursi, Vitullo, Ucchino, Spigonardo, Ciabattoni, F. Cuccurullo, and Mezzetti); University of Palermo, Palermo, Italy (Drs Averna and Notarbartolo); University of Rome La Sapienza, Rome, Italy (Drs Arca and
Campagna and Ms Montali); and the University of Pisa, Pisa, Italy (Drs Taddei and Virdis).

A complete list of the INES Study Group members is listed at the end of this article.

Corresponding Author: Andrea Mezzetti, MD, Nuovo Policlinico SS Annunziata, Centro Regionale per la Prevenzione dell'Aterosclerosi, Via dei Vestini 66, 66013 Chieti, Italy (mezzetti@unich.it). 


\begin{tabular}{|c|c|c|}
\hline Characteristics & $\begin{array}{l}\text { Cases } \\
(n=864)\end{array}$ & $\begin{array}{l}\text { Controls } \\
(\mathrm{n}=864)\end{array}$ \\
\hline Age, mean (SD), y & $62.7(10)$ & $62.9(8)$ \\
\hline Male/female & $579(67) / 285(33)$ & $553(64) / 311(36$ \\
\hline Hypercholesterolemia & $449(52)$ & $432(50)$ \\
\hline Hypertension & $380(44)$ & $389(45)$ \\
\hline Diabetes & $156(18)$ & $147(17)$ \\
\hline Cigarette smoking & $311(36)$ & $302(35)$ \\
\hline Body mass index, mean (SD) $\dagger$ & $27(6)$ & $27(7)$ \\
\hline NSAID or glucocorticoid treatment & 0 & 0 \\
\hline Aspirin treatment & $578(67)$ & $535(62)$ \\
\hline Angiographically proven CAD $(n=750)$ & $320(76.2)$ & $253(76.8)$ \\
\hline Single-vessel disease & $127(30.2)$ & $96(29)$ \\
\hline 2-Vessel disease & $98(23.3)$ & 79 (23.9) \\
\hline 3-Vessel disease & $95(22.7)$ & $73(22.1)$ \\
\hline $\begin{array}{l}\text { ICA stenosis severity ( } \mathrm{n}=232), \% \\
\text { Mean (SD) }\end{array}$ & $74(5)$ & $74(6)$ \\
\hline Range & $70-92$ & $70-91$ \\
\hline \multicolumn{3}{|c|}{$\begin{array}{l}\text { Abbreviations: CAD, coronary artery disease; ICA, internal carotid artery; NSAID, nonsteroidal anti- } \\
\text { inflammatory drug. } \\
\text { *Data are expressed as No. (\%) unless otherwise indicated. } \\
\text { †Body mass index was calculated as weight in kilograms divided by the square of height in meters. }\end{array}$} \\
\hline
\end{tabular}

dividual's genetic makeup and environmental factors. ${ }^{2,3}$ Increasing evidence supports a central role for inflammation in the cascade of events that results in plaque fissuring. ${ }^{4,5} \mathrm{Le}-$ sion macrophages synthesize matrix metalloproteinases (MMPs); in particular, 72-kDa (MMP-2) and 92-kDa (MMP-9) gelatinase, proteolytic enzymes capable of degrading plaque constituents. ${ }^{6}$ We recently reported that enhanced MMP-2 and MMP-9 production by macrophages in vulnerable plaques is due to enhancement in prostaglandin $E_{2}\left(P_{G E}\right)$ synthesis as a result of the induction of COX-2..$^{6-9}$

Recently, Papafili et $\mathrm{al}^{10}$ and Cipollone and Patrono ${ }^{11}$ identified a new variant in the COX-2 promoter, a guanine to cytosine substitution at position -765 $(-765 G \rightarrow C)$, and showed that this variant is located within a putative binding site for the transcription factor Spl. Patients carrying the $-765 \mathrm{C}$ allele had markedly (30\%) lower promoter activity and lower plasma levels of C-reactive protein (CRP), a marker of low-grade inflammation, compared with patients homozygous for $-765 \mathrm{G}$.

Because lower COX-2 activity could reduce generation of culprit MMPs in plaques, and because CRP is closely re- lated to cardiovascular risk, ${ }^{12}$ we hypothesized that $-765 \mathrm{G} \rightarrow \mathrm{C}$ might be protective against plaque instability, leading to lower risk of MI and stroke. We therefore prospectively performed a case-control study in which we genotyped this locus in 1728 individuals at high risk of cardiovascular events (864 patients with well-characterized previous MI or stroke and 864 controls).

\section{METHODS \\ Study Participants}

The study participants comprised 1728 unrelated Italian patients who were admitted to 4 participating hospitals (SS Annunziata University Hospital of Chieti, University Hospital of Palermo, S Chiara University Hospital of Pisa, and La Sapienza University Hospital of Rome, all in Italy) between March 2002 and October 2003 and who had at least 1 conventional risk factor for cardio-

Cases $(n=864)$ were patients who had had a first-event MI or ischemic stroke. We specifically focused on ischemic strokes that were atherothrombotic and related to ulceration of a culprit internal carotid artery lesion. We made every effort to exclude patients with other subtypes of ischemic stroke vascular disease. by clinical examination and laboratory and imaging analyses. In particular, strokes had to be in the territory of the mid cerebral artery as documented by computed tomographic scan and cerebral angiography. All patients had Doppler evidence of an ulcerated culprit lesion in the internal carotid artery as well as preprocedural transcranial Doppler analysis of cerebral blood flow strongly indicative of active thromboembolism. Finally, all study participants were in sinus rhythm at the time of hospitalization and had no history of atrial fibrillation.

Controls $(\mathrm{n}=864)$ were high-risk patients prospectively matched for risk factors and concomitant therapy, as shown in TABLE 1, who had no history of MI, unstable angina, transient ischemic attack, or stroke and were hospitalized for any clinical reason except MI, unstable angina, transient ischemic attack, or stroke. Controls were hospitalized within 1 year of case hospitalizations.

Among the 1728 patients enrolled in the study, 232 ( 102 cases [ $11.8 \%$ ] and 130 controls [15\%]) underwent carotid endarterectomy and 750 (420 cases [48\%] and 330 controls [38\%]) underwent coronary angiography during their hospitalization as part of their routine clinical care. Furthermore, serum high-sensitivity CRP (hsCRP) (Immulyte, Diagnostic Product Corp) was measured and compared in a subgroup of 224 cases with -765 GG vs -765GC genotypes.

The protocol was approved by local ethics review committees. Written informed consent was obtained from all patients prior to study enrollment and before each examination.

\section{Data Collection and Analysis}

Blood and urine samples were collected from all participants after an overnight fast, and multiple aliquots of whole blood, plasma, serum, and urine were immediately stored at $-80^{\circ} \mathrm{C}$ until analysis.

Genomic DNA was prepared from frozen whole blood with the use of a blood DNA isolation kit (Helix Fast 
Table 2. Characteristics of In Vitro Substudy Participants by Genotype and Clinical History*

\begin{tabular}{|c|c|c|c|c|c|c|}
\hline \multirow[b]{2}{*}{ Characteristics } & \multicolumn{2}{|c|}{$-765 G G$} & \multicolumn{2}{|c|}{$-765 G C$} & \multicolumn{2}{|c|}{$-765 \mathrm{CC}$} \\
\hline & $\begin{array}{l}\text { Cases } \\
(\mathrm{n}=5)\end{array}$ & $\begin{array}{c}\text { Controls } \\
(n=5)\end{array}$ & $\begin{array}{l}\text { Cases } \\
(n=5)\end{array}$ & $\begin{array}{l}\text { Controls } \\
(n=5)\end{array}$ & $\begin{array}{l}\text { Cases } \\
(\mathrm{n}=5)\end{array}$ & $\begin{array}{c}\text { Controls } \\
(n=5)\end{array}$ \\
\hline Age, mean (SD), y & $63(7)$ & $64(7)$ & $61(10)$ & $62(7)$ & $64(8)$ & $62(6)$ \\
\hline Male/female, No. & $3 / 2$ & $4 / 1$ & $3 / 2$ & $3 / 2$ & $4 / 1$ & $4 / 1$ \\
\hline Hypercholesterolemia & 2 & 3 & 3 & 3 & 2 & 2 \\
\hline Hypertension & 4 & 3 & 3 & 3 & 3 & 3 \\
\hline Diabetes & 2 & 2 & 2 & 1 & 2 & 2 \\
\hline Cigarette smoking & 2 & 1 & 2 & 1 & 1 & 3 \\
\hline Body mass index, mean (SD)† & $26(7)$ & $27(5)$ & $26(4)$ & $28(6)$ & $28(5)$ & $26(7)$ \\
\hline Aspirin treatment & 5 & 3 & 4 & 3 & 5 & 3 \\
\hline $\begin{array}{l}\text { ICA stenosis severity, \% } \\
\text { Mean (SD) }\end{array}$ & $90(2)$ & $92(2)$ & $93(3)$ & $91(1)$ & $90(4)$ & $90(2)$ \\
\hline Range & $72-94$ & $70-93$ & $73-92$ & $72-91$ & $70-92$ & $73-91$ \\
\hline
\end{tabular}

Blood DNA, DiaTech, Jesi, Italy). The $-765 \mathrm{G} \rightarrow \mathrm{C}$ variant was genotyped by FAU I (Celbio, Milan, Italy) restriction endonuclease digestion of the polymerase chain reaction product (Figure 1). Genotypes were determined by independent investigators who were blinded to patients' identities and phenotypes.

After carotid endarterectomy, plaque sections were prepared and analyzed by immunohistochemistry using a color image analysis system (AlphaEase 5.02, Alpha Innotech Corp, San Leandro, Calif), as previously described. ${ }^{6}$

As previously described, ${ }^{6}$ Western blot analysis on plaque extracts and plaque-derived macrophages was performed to detect COX-2, MMP-2, and MMP-9 expression; concurrent immunodetection of $\beta$-actin was performed to ensure equal gel loading. Bands were quantified by computer-assisted densitometry (AlphaEase 5.02) and expressed as densitometric units (DU).

Zymography on plaque extract and plaque-derived macrophages was performed to detect MMP-2 and MMP-9 gelatinolytic activity, as previously described. ${ }^{6}$ Conditioned medium of human fibrosarcoma cell line HT1080 was used as a positive control with known gelatinolytic activity.

Sirius red polarization microscopy was used to detect type 1 and 3 interstitial collagen in plaque sections ac- cording to a previously described method. ${ }^{9}$

Macrophages were selectively extracted from plaques as described by de Vries et al. ${ }^{13}$ Flow cytometry analysis of purified cell preparations using a phycoerythrin-conjugated antiCD68 monoclonal antibody (Clone Y1/ 82A, BD Biosciences PharMingen, San Diego, Calif) showed that more than 98\% of the selected cells were positive for CD68. Then, immunocytochemistry, Western blot, and zymography were performed. Results are representative of 3 different analyses (intrasample tests for in vitro reproducibility).

Peripheral blood monocytes were purified and cultured from 10 randomly selected patients carrying the $-765 \mathrm{GG}$ genotype, 10 carrying the $-765 \mathrm{GC}$ genotype, and 10 carrying the $-765 \mathrm{CC}$ genotype. ${ }^{6}$ In particular, to create 3 homogeneous groups, patients were selected not only on the basis of genotype but also on the basis of clinical features. Thus, for each genotype, 5 control patients and 5 case patients were selected (TABLE 2). Monocytes $\left(20 \times 10^{6} / 4 \mathrm{~mL}\right.$ of Dulbecco modified eagle's medium) were stimulated with lipopolysaccharide ( $1 \mu \mathrm{g} / \mathrm{mL})$, oxidized low-density lipoprotein (LDL) $(50 \mu \mathrm{g} / \mathrm{mL})$, angiotensin II $\left(10^{-7} \mathrm{~mol} / \mathrm{L}\right)$, and advanced glycation end products ( $800 \mu \mathrm{g} / \mathrm{mL}$ ) as previously described..$^{6,9,14}$ At the end of the incuba- tion, COX-2 and MMP expression was evaluated by Western blot, MMP activity by zymography, and $\mathrm{PGE}_{2}$ (Cayman Chemical, Ann Arbor, Mich) and MMP-9 (Amersham Biosciences, Piscataway, NJ) release by enzymelinked immunosorbent assay.

In vivo prostacyclin $\left(\mathrm{PGI}_{2}\right)$ production, a process largely dependent on COX-2 activity in endothelium, ${ }^{15,16}$ was analyzed in 8 randomly selected participants with the $-765 \mathrm{GG}$ genotype, 8 with $-765 \mathrm{GC}$, and 8 with $-765 \mathrm{CC}$ by measuring urinary excretion of 6-keto $\mathrm{PGF}_{1 \alpha}$, the major urinary metabolite of renal $\mathrm{PGI}_{2}$, according to a previously described radioimmunoassay. ${ }^{17}$ Straingauge plethysmography was used to measure forearm blood flow changes induced by intrabrachial acetylcholine and sodium nitroprusside according to a previously validated method ${ }^{18}$ in 6 randomly selected control participants with the $-765 \mathrm{GG}$ genotype, 9 with $-765 \mathrm{GC}$, and 3 with $-765 \mathrm{CC}$ to identify perturbations in endotheliumdependent vasodilation.

\section{Statistical Analyses}

The significance of differences in biochemical marker expression and inflammatory cell infiltration among the 3 genotypes was analyzed by unpaired $t$ test. Discrete data (including prevalence of the $-765 \mathrm{C}$ allele in cases and controls) were analyzed by the $\chi^{2}$ test, 
with the allele frequency predicted on the basis of the Hardy-Weinberg equilibrium. We used logistic regression modeling to test the association of the COX-2 polymorphisms on the risk of MI and ischemic stroke ${ }^{19}$ after adjusting for age, body mass index, smoking status, hypertension, diabetes mellitus, and hypercholesterolemia. All analyses were performed using SPSS software, version 11.0.1 (SPSS Inc, Chicago, Ill) ${ }^{20} \mathrm{P}<.05$ was considered statistically significant.

\section{RESULTS}

\section{Characteristics of the Study Participants}

The characteristics of the 1728 study participants are shown in Table 1 . There were no significant differences between cases and controls in age, body mass index, or prevalence of conventional risk factors for cardiovascular disease.

\section{Prevalence of the $-765 G \rightarrow C$ Polymorphism}

TABLE 3 summarizes the genotype data for all study participants. The prevalence of the -765GC genotype was 2.41 times higher among controls than among cases (prevalence ratio, 0.48; 95\% confidence interval $[\mathrm{CI}], 0.36-0.68)$. The prevalence of $-765 \mathrm{CC}$ homozygosity was 5.81 times higher (prevalence ratio, 0.33 ; 95\% CI, 0.24-0.55). The inverse association between $-765 \mathrm{G} \rightarrow \mathrm{C}$ variant and cardiovascular events was even stronger in patients older than 70 years, suggesting that participants carrying the $-765 \mathrm{G} \rightarrow \mathrm{C}$ variant have a higher probability of healthy aging. In the subgroup of 187 participants with 1 firstdegree relative who had had MI or ischemic stroke, the prevalence of one -765 C allele was 4.3 times higher among asymptomatic controls than among cases. There were no differences in the frequency of the -765GC genotype be-

Table 3. Distributions and Results of Multivariable Logistic Regression Analyses of COX-2 Gene Variants Among Cases and Controls With MI or Atherothrombotic Ischemic Stroke

\begin{tabular}{|c|c|c|c|c|c|}
\hline \multirow[b]{2}{*}{ Genotype } & \multicolumn{2}{|c|}{ Distribution, \% } & \multirow{2}{*}{$\begin{array}{c}\text { Ratio, } \\
\text { Controls/ } \\
\text { Cases }\end{array}$} & \multirow{2}{*}{$\begin{array}{c}\text { Prevalence } \\
\text { Ratio } \\
(95 \% \mathrm{Cl})^{*}\end{array}$} & \multirow{2}{*}{$\begin{array}{c}P \\
\text { Value }\end{array}$} \\
\hline & Controls & Cases & & & \\
\hline \multicolumn{6}{|l|}{ All participants $(n=1728)$} \\
\hline GG & 50.7 & 81 & 0.62 & & $<.001$ \\
\hline $\mathrm{GC}$ & 43.3 & 17.9 & 2.41 & $0.48(0.36-0.68)$ & $<.001$ \\
\hline $\mathrm{CC}$ & 6.4 & 1.1 & 5.81 & $0.33(0.24-0.55)$ & .04 \\
\hline \multicolumn{5}{|l|}{ Allele frequency } & \\
\hline G & 0.748 & 0.896 & & & \\
\hline \multicolumn{6}{|c|}{$\begin{array}{l}\text { Participants aged }>70 \text { y }(n=257 ; \\
112 \text { controls and } 145 \text { cases) }\end{array}$} \\
\hline $\mathrm{GC}$ & 41.2 & 9.7 & 4.2 & $0.44(0.33-0.78)$ & $<.001$ \\
\hline $\mathrm{CC}$ & 7.5 & 1.1 & 6.8 & $0.31(0.21-0.63)$ & .008 \\
\hline $\begin{array}{l}\text { Allele frequency } \\
\text { C }\end{array}$ & 0.273 & 0.104 & & & \\
\hline $\mathrm{G}$ & 0.727 & 0.896 & & & \\
\hline \multicolumn{6}{|c|}{$\begin{array}{l}\text { Participants with first-degree relative } \\
\text { with previous acute Ml or stroke } \\
\text { ( } \mathrm{n}=187 ; 84 \text { controls and } 103 \\
\text { cases) }\end{array}$} \\
\hline $\mathrm{GG}$ & 47.9 & 88.9 & 0.54 & & $<.001$ \\
\hline GC & 44.3 & 10.3 & 4.3 & $0.41(0.29-0.64)$ & $<.001$ \\
\hline$\overline{\mathrm{CC}}$ & 7.8 & 0.8 & 9.75 & $0.30(0.22-0.52)$ & .004 \\
\hline $\begin{array}{l}\text { Allele frequency } \\
\text { C }\end{array}$ & 0.279 & 0.089 & & & \\
\hline $\mathrm{G}$ & 0.721 & 0.911 & & & \\
\hline
\end{tabular}

Abbreviations: $\mathrm{Cl}$, confidence interval; COX-2, cyclooxygenase 2; Ml, myocardial infarction.

*The prevalence ratio is for the cumulative risk of $\mathrm{Ml}$ and atherothrombotic ischemic stroke among patients who were heterozygous or homozygous for the $-765 \mathrm{G} \rightarrow$ C polymorphism compared with those who were not, calculated based on the odds ratio from logistic regression after adjustment for confounders. ${ }^{20}$ tween the 2 subgroups defined according to diagnosis of MI or stroke (17.9\% and $17.8 \%$, respectively).

\section{Inverse Association Between $-765 G \rightarrow$ C Polymorphism and $\mathrm{MI}$ or Stroke}

Homozygosity as well as heterozygosity for the $-765 \mathrm{C}$ allele was associated with a markedly lower risk of MI and stroke. Patients with the $-765 \mathrm{GC}$ or -765 CC genotype had a reduction in relative risk of MI and ischemic stroke of $52 \%$ and $67 \%$, respectively, after adjustment for age, sex, smoking status, body mass index, hypercholesterolemia, hypertension, and diabetes (Table $3)$. The same was true when we analyzed patients who underwent carotid endarterectomy or coronary angiography as case-control substudies (carotid endarterectomy, adjusted prevalence ratio, 0.46; 95\% CI, 0.34-0.69; $P=.03$; coronary angiography, prevalence ratio, $0.34 ; 95 \% \mathrm{CI}, 0.26-0.58 ; P=.04$ ).

To investigate the association of the COX-2 polymorphism with plaque growth, we analyzed the atherosclerotic burden as a function of the $-765 \mathrm{C}$ allele in patients who had accurate quantification of atherosclerosis by carotid Doppler or coronary angiography. We did not find any association between the $-765 \mathrm{C}$ allele and severity of atherosclerosis at either the carotid or the coronary level (Table 1). Nonetheless, in a subgroup of 224 cases, mean (SD) serum hsCRP was significantly lower in patients with the $-765 \mathrm{C}$ allele $(0.78[0.1]$ $\mathrm{mg} / \mathrm{L}$ vs 2.56 [0.4] $\mathrm{mg} / \mathrm{L} ; P=.04)$.

\section{COX-2 Expression in Carotid Plaques of Patients With the $-765 \mathrm{G} \rightarrow$ C Polymorphism}

COX-2 staining was significantly more abundant in $-765 \mathrm{GG}$ carotid plaques (FIGURE 1), as confirmed by quantitative analysis (mean [SD], 23\% [2\%], 16\% [2\%], and $10 \%$ [1\%] for $-765 \mathrm{GG}$ $(\mathrm{n}=145),-765 \mathrm{GC}(\mathrm{n}=78)$, and $-765 \mathrm{CC}$ $(\mathrm{n}=9)$, respectively; $P<.001)$. COX-2 accumulated mainly in macrophages. Western blot confirmed higher COX-2 expression in $-765 \mathrm{GG}$ plaques (8576 [176] DU, 5132 [142] DU, and 3059 
[117] DU for $-765 G G,-765 G C$, and $-765 C$ C , respectively; $P<.001$ ) (FIGURE 2). These observations remained consistent when separate analyses for the case and control groups were performed. To exclude the possibility that observed discrepancies in COX-2 expression were merely a secondary effect of differences in inflammatory infiltration, we repeated immunocytochemistry and Western blot analyses on macrophages that had been selectively extracted from plaques. We again noted that plaque macrophages from patients carrying the $-765 \mathrm{G} \rightarrow \mathrm{C}$ polymorphism had a lower COX-2 expression.

\section{MMP Expression and Activity in Carotid Plaques of Patients With the $-765 G \rightarrow C$ Polymorphism}

Staining for MMP-2 and MMP-9 was significantly more abundant in $-765 \mathrm{GG}$ lesions $(n=145)$ than in $-765 G C(n=78)$ and $-765 \mathrm{CC}$ plaques $(\mathrm{n}=9)$ (mean [SD], $22 \%$ [3\%] vs $15 \%$ [2\%] and 9\% [2\%], respectively, for MMP-2; $24 \%$ [4\%] vs $13 \%$ [2\%] and $8 \%$ [ $1 \%$ ], respectively, for MMP-9; all $P<.003$ ) (Figure 1 ). Increased MMP immunoreactivity was also documented by Western blot in -765GG plaques compared with $-765 \mathrm{GC}$ and $-765 C C$ plaques $(n=232)$ (mean [SD], 7165 [134] DU vs 5121 [78] DU and 3978 [67] DU for MMP-2; 8090 [187] DU vs 6012 [102] DU and 4765 [95] DU for MMP-9; all $P<.003$ ) (Figure 2). Zymography demonstrated that extracts from $-765 G G$ plaques $(n=145)$ contained higher amounts of activated forms of MMP-2 and MMP-9 than -765GC $(\mathrm{n}=78)$ and $-765 \mathrm{CC}(\mathrm{n}=9)$ plaques (mean [SD], 3012 [134] DU vs 1898 [104] DU and 1342 [54] DU for MMP-2; 3867 [165] DU vs 2011 [89] DU and 1223 [65] DU for MMP-9; $P<.001$ ) (Figure 2).

\section{Collagen Content in Plaques of Patients With the $-765 G \rightarrow$ C Polymorphism}

Sirius red polarization showed considerably lower content of interstitial collagen in the tissue sections of patients carrying the -765GG genotype compared with patients carrying the -765 GC and $-765 C C$ genotypes $(n=232)$ (mean $[S D], 9 \%[1 \%]$ vs $15 \%$ [2\%] [P=.002] and 19\% [3\%] [P=.003], respectively).

\section{Inflammatory and Proteolytic \\ Response in Monocytes/ Macrophages of Patients With the -765G $\rightarrow$ C Polymorphism}

In monocytes isolated from patients carrying the -765 GG genotype, lipopolysaccharide, oxidized low-density lipoprotein, angiotensin II, and advanced glycation end products induced significant increases in COX-2, MMP-2, and

Figure 1. Immunohistochemical Analysis for Presence of COX-2 and MMP-9 in Atherosclerotic Carotid Plaques

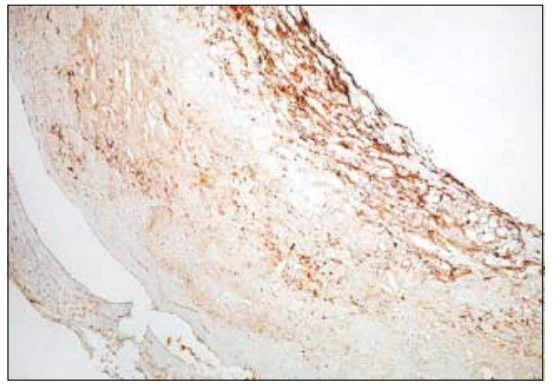

Immunohistochemical Analysis for Presence of COX-2
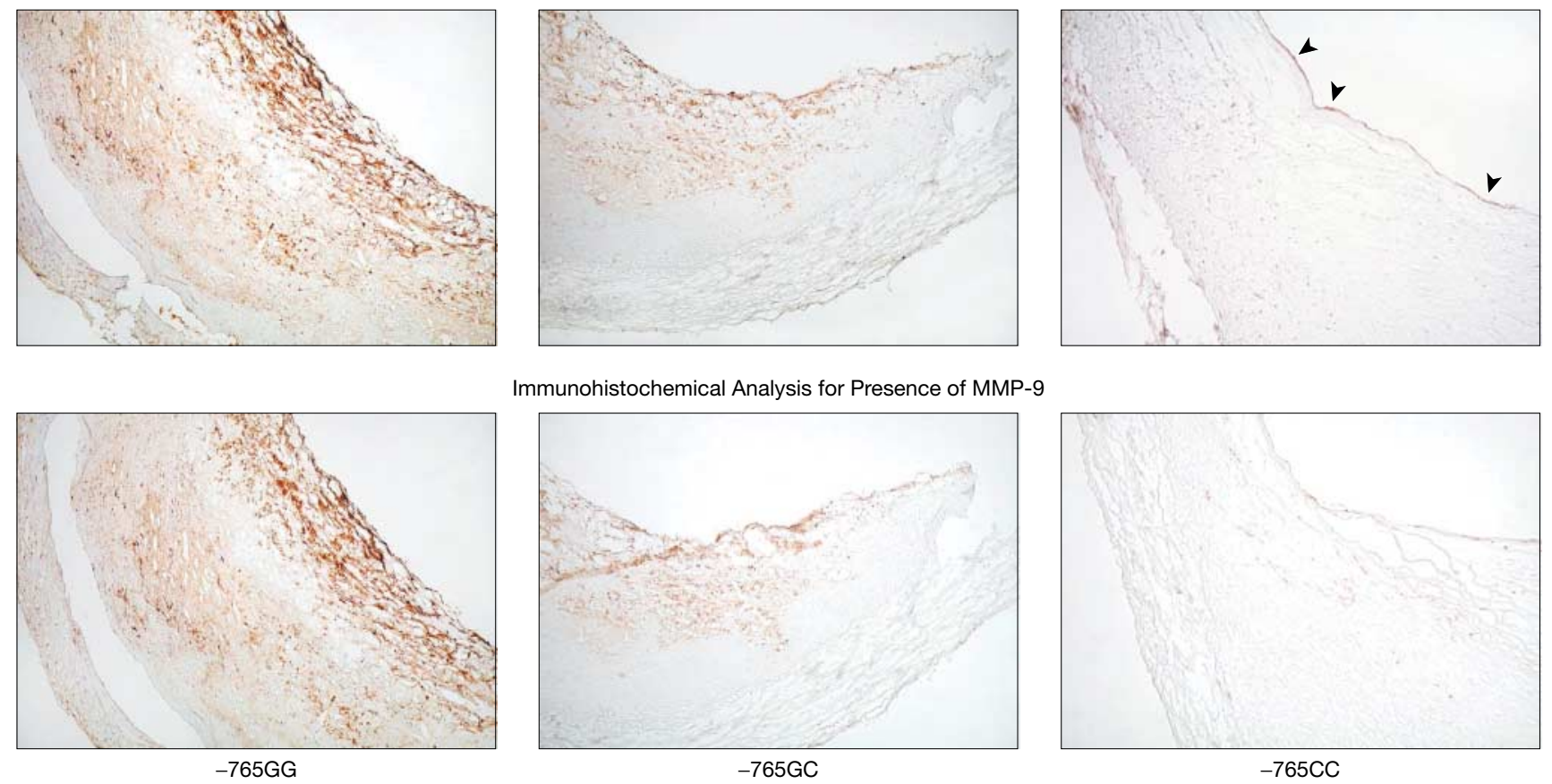

Immunohistochemical Analysis for Presence of MMP-9
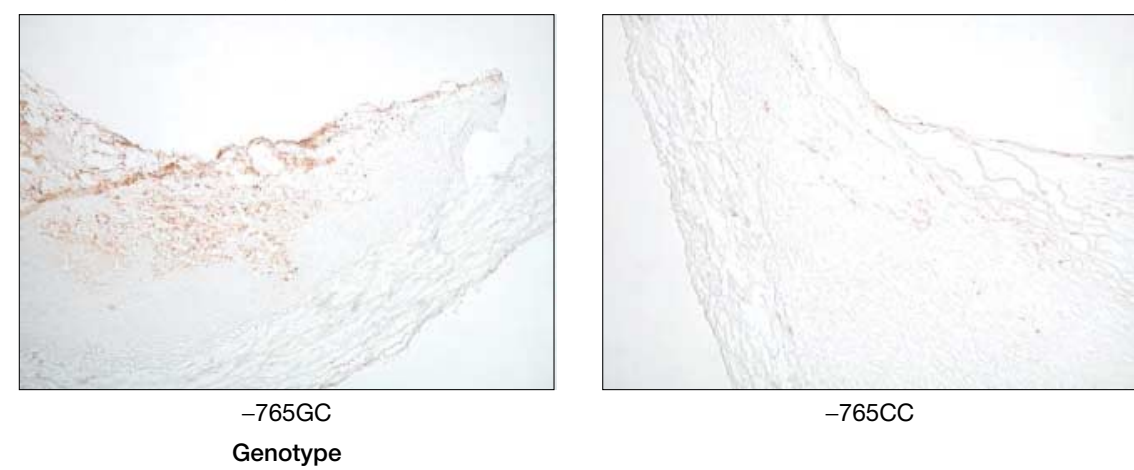

Cyclooxygenase 2 (COX-2) and matrix metalloproteinase 9 (MMP-9) protein expression by biotin-streptavidin immunohistochemical analysis using 2 monoclonal human antibodies to COX-2 and MMP-9, respectively, in plaques obtained by endarterectomy from patients carrying the -765 GG, -765 GC, and -765 CC genotypes. Top and bottom panels show similar regions of the plaque. Brown chromogen indicates positive staining of COX-2 and MMP-9. Note the endothelium (arrows) in the -765 CC plaque, characterized by strong expression of COX-2, in contrast with the reduced expression of COX-2 in infiltrating macrophages beneath the endothelial layer (counterstain, hematoxylin; original magnification $\times 20$ ). 
Figure 2. Western Blot and Zymography Analyses for COX-2 and MMP in Atherosclerotic Carotid Plaques After Endarterectomy

A Western Blot Analysis

COX-2 (70 kDa)

MMP-9 (92 kDa)

$\beta$-Actin (42 kDa) (Reference)

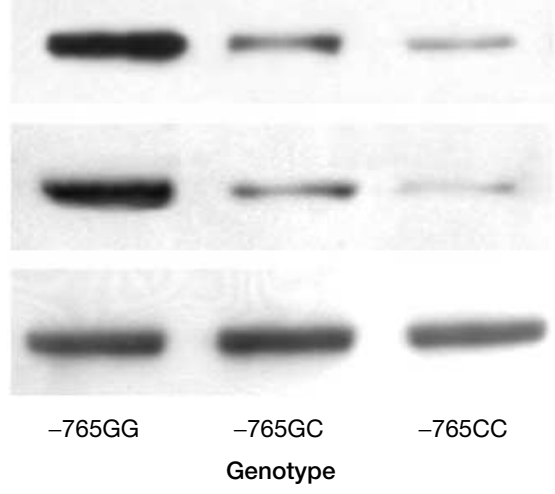

B Zymography

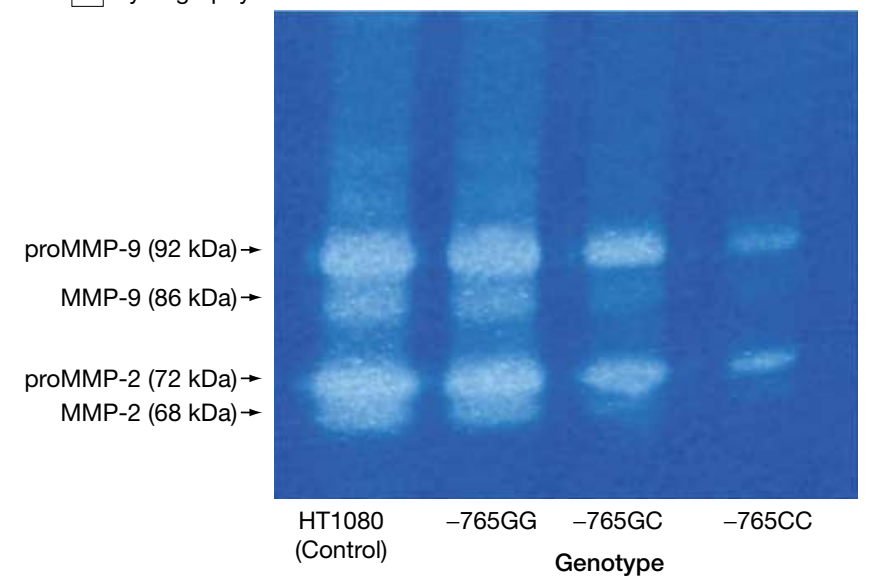

A, Western blot for cyclooxygenase 2 (COX-2) and matrix metalloproteinase 9 (MMP-9) and B, identification of gelatinolytic activity of activated MMP-9, MMP-2, and their precursor forms (proMMP-9 and proMMP-2) by zymography in plaque extracts from patients carrying the -765 GG, -765 GC, and -765 CC genotypes. Fibrosarcoma cell line HT1080 was used as a positive control.

Figure 3. Western Blot Analysis of COX-2 Expression in Monocytes in Different Culture Environments

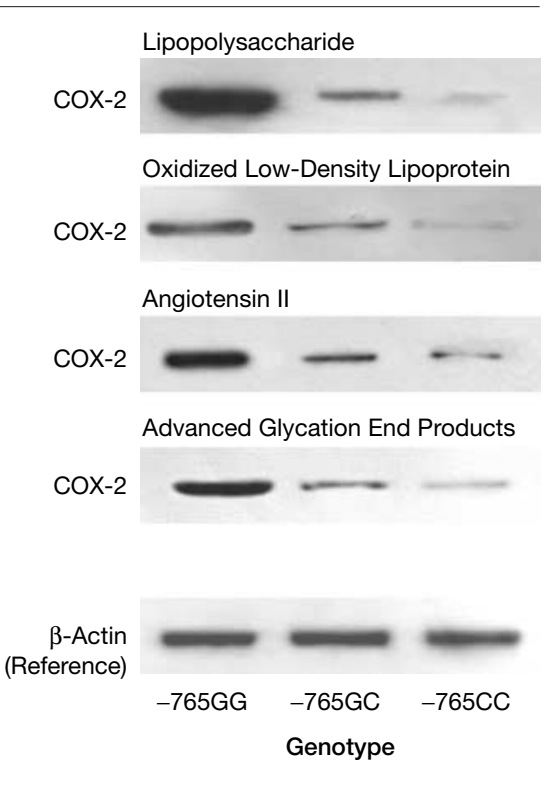

Purified monocytes carrying the -765 GG, -765 GC, and -765 CC genotypes were cultured in the presence of lipopolysaccharide, oxidized low-density lipoprotein, angiotensin II, and advanced glycation end products. The cultures were harvested at 48 hours for Western blot analysis of cyclooxygenase 2 (COX-2) expression.

MMP-9 protein expression (FIGURE 3) as well as in $\mathrm{PGE}_{2}$ (mean [SD], 4.25 [0.3], $2.86[0.2]$, and $1.64[0.2] \mathrm{ng} / \mathrm{mL}$, respec- tively, after lipopolysaccharide, $1 \mu \mathrm{g} /$ $\mathrm{mL}$ ) and MMP-9 (mean [SD], 30.3 [4.0], 21.4 [3.0], and 12.6 [2.0] ng/mL, respectively, after lipopolysaccharide, $1 \mu \mathrm{g} /$ $\mathrm{mL}$ ) release compared with that detected in monocytes from patients carrying the $-765 \mathrm{GC}$ and $-765 \mathrm{CC}$ genotypes. Similar results were also observed in plaque-derived macrophages.

\section{-765G $\rightarrow$ C Polymorphism and $\mathbf{P G I}_{2}$ Biosynthesis and Endothelial Function In Vivo}

Urinary 6-keto $\mathrm{PGF}_{1 \alpha}$ excretion was not different in patients carrying the -765GG genotype compared with patients carrying the $-765 \mathrm{GC}$ and -765CC genotypes (mean [SD], 9.7 [1.0] ng/h vs 9.3 [2.2] ng/h [P=.65] and $10.5[1.0] \mathrm{ng} / \mathrm{h}[P=.13])$. Similarly, no differences in endotheliumdependent and endotheliumindependent (sodium nitroprusside) vasodilation were observed among participants carrying the 3 genotypes (FIGURE 4).

\section{COMMENT}

We found that the $-765 \mathrm{G} \rightarrow \mathrm{C}$ polymorphism of the COX-2 gene is associated with a reduction in the risk of MI and stroke, suggesting that this allele may offer protection against clinical events related to atherosclerotic plaque rupture.

The prevalence distribution of this polymorphism in our control group was significantly higher than that recently reported by Papafili et $\mathrm{al}^{10}$ in a smaller sample in the United Kingdom. Since the $-765 \mathrm{G} \rightarrow \mathrm{C}$ polymorphism is associated with lower expression and activity of the COX-2 gene in plaque macrophages, the finding of a lower frequency of this polymorphism in the United Kingdom is consistent with the higher incidence of MI and stroke in that country compared with in Italy. In addition, it could explain, at least in part, the higher risk of MI observed in northern Europe compared with Mediterranean populations with similar levels of cholesterol and blood pressure. ${ }^{21}$

Both the -765GC and -765CC genotypes were significantly related to COX-2 expression and activity in circulating blood monocytes and carotid plaque macrophages, suggesting that the association between COX-2 genotype and MI and stroke may occur as a result of the modulation of COX-2 activity in inflammatory cells. Indeed, patients with the -765CC genotype, who had the lowest risk of MI and stroke, also had the lowest level of COX-2 expression and activity in plaque 
sections, in plaque-derived macrophages, and in circulating blood monocytes. Furthermore, the presence of at least one $-765 \mathrm{C}$ allele was associated with a significant reduction in serum CRP, thus suggesting that this polymorphism may also influence systemic inflammatory status.

The precise mechanism by which the COX-2 polymorphism may affect the risk of MI and stroke is unclear. Both MI and atherothrombotic stroke are often triggered by rupture of vulnerable atherosclerotic plaques, with the propensity of rupture enhanced by $\mathrm{PGE}_{2}-$ dependent MMPs. ${ }^{22}$ Thus, the marked reduction in plaque MMPs observed in patients carrying the $-765 \mathrm{G} \rightarrow \mathrm{C}$ polymorphism supports our hypothesis that reduction of MMP biosynthesis as a consequence of lower $\mathrm{PGE}_{2}$ generation may explain the risk reduction we observed. The lower COX-2 induction observed in monocytes and macrophages of patients carrying the $-765 \mathrm{C}$ allele after stimulation with oxidized low-density lipoprotein, angiotensin II, and advanced glycation end products (stimuli upregulated in the setting of hypercholesterolemia ${ }^{23}$ hypertension, ${ }^{24}$ and diabetes, ${ }^{14}$ respectively) is also consistent with the possibility that the $-765 \mathrm{G} \rightarrow \mathrm{C}$ polymorphism may be protective against MI and stroke. However, we cannot exclude that other important mechanisms-for example, the reduction of aspirin-insensitive thromboxane biosynthesis in circulating monocytes ${ }^{25}$ - may also contribute to the risk reduction associated with the $-765 C$ allele. ${ }^{26-28}$ Furthermore, because adjustment for baseline risk factors was not performed in these in vitro substudies, we cannot exclude a potential influence of selection bias.

We did not find differences in the severity of atherosclerotic lesions among patients carrying the 3 different genotypes. This observation confirms previous studies suggesting that COX- 2 is involved in the evolution of atherosclerotic plaque toward instability ${ }^{6,9,14}$ rather than plaque growth. ${ }^{29,30}$

We noted that the $-765 \mathrm{G} \rightarrow \mathrm{C}$ polymorphism was not associated with en- dothelial generation of $\mathrm{PGI}_{2}$ and endothelium-dependent vasodilation. This is consistent with previous observations in epithelial cells ${ }^{11}$ and suggests that transcription factor Spl has differing roles regarding induction of COX-2 in monocytes and macrophages compared with endothelial and epithelial cells. Because $\mathrm{PGI}_{2}$ is considered a potent antiatherogenic mediator, ${ }^{31}$ these data strengthen support for the protective role of the $-765 \mathrm{G} \rightarrow \mathrm{C}$ polymorphism and point out a major difference with respect to COX-2 inhibition through COX-2 inhibitors (coxibs), which also inhibit COX-2 at the endothelial level..$^{15,16}$

Our study also raises a number of provocative questions regarding the potential clinical importance of this genotype in asymptomatic patients taking selective coxibs. The individual pharmacodynamic response to COX-2 inhibitors may vary, ${ }^{32}$ as responders and nonresponders to coxibs have been described. ${ }^{33,34}$ Thus, patients with the -765 GC and -765CC genotypes may represent subgroups of patients with different drug responses.

Further research will be needed to determine whether genotyping patients for the COX-2 polymorphism leads to better treatment outcomes.

In conclusion, consistent with the presence of genetic determinants of clinical atherosclerotic risk, we found that the $-765 \mathrm{G} \rightarrow C$ polymorphism of the COX-2 gene is associated with a lower risk of MI and ischemic stroke. The reduction in risk may be related to modification of COX-2 expression in plaque macrophages. Further studies are necessary to identify additional polymorphisms in the arachidonic acid pathway that are associated with risk of MI and stroke.

Author Contributions: Dr Cipollone had full access to all of the data in the study and takes responsibility for the integrity of the data and the accuracy of the data analysis.

Study concept and design: Cipollone, Martinotti, F. Cuccurullo, Mezzetti.

Acquisition of data: Cipollone, Toniato, Fazia, lezzi, Pini, Ursi, Vitullo, Averna, Arca, Montali, Campagna, Ucchino, Spigonardo, Taddei, Virdis, Ciabattoni, Notarbartolo, C. Cuccurullo.

Analysis and interpretation of data: Cipollone, Martinotti, F. Cuccurullo, Mezzetti.
Figure 4. Influence of $-765 \mathrm{G} \rightarrow \mathrm{C}$ Polymorphism on Cyclooxygenase 2 Activity in Endothelium

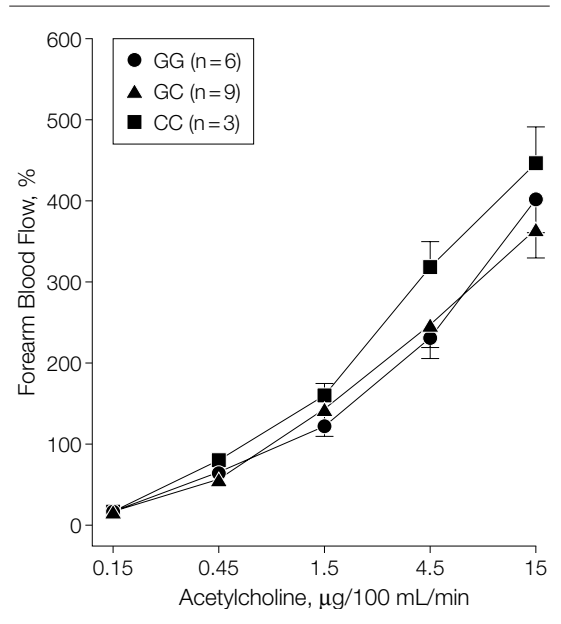

Mean increase in the forearm blood flow induced by acetylcholine in participants carrying the $-765 \mathrm{GG}$, -765 GC, and -765 CC genotypes. No differences in endothelium-dependent and -independent (sodium nitroprusside) vasodilation were observed among participants carrying the 3 genotypes. Error bars indicate SD.

Drafting of the manuscript: Cipollone, Martinotti, F. Cuccurullo, Mezzetti.

Critical revision of the manuscript for important intellectual content: Cipollone, Toniato, Martinotti, Fazia, lezzi, C. Cuccurullo, Pini, Ursi, Vitullo, Averna, Arca, Montali, Campagna, Ucchino, Spigonardo, Taddei, Virdis, Ciabattoni, Notarbartolo, F. Cuccurullo, Mezzetti.

Statistical expertise: Cipollone.

Obtained funding: Cipollone, Cuccurullo, Mezzetti. Administrative, technical, or material support: Toniato, Fazia, lezzi, Cuccurullo, Ursi, Vitullo, Montali, Campagna, Virdis, Ciabattoni.

Supervision: Cipollone, Martinotti, F. Cuccurullo, Mezzetti.

Members of the INES Study Group: Francesco Cipollone, MD, Elena Toniato, PhD, Stefano Martinotti, MD, Maria Fazia, PhD, Annalisa lezzi, MD, Chiara Cuccurullo, MD, Barbara Pini, MD, Sebastiano Ursi, PhD, Gianfranco Vitullo, MD, Mirco Zucchelli, PhD, Alessandro Allegrini, PhD, Domenico De Cesare, Tch, Marianna Germano, Tch, Andrea Tavella Scaringi, PhD, Giovanni Ciabattoni, MD, Sante Ucchino, MD, Francesco Spigonardo, MD, Franco Cuccurullo, MD, and Andrea Mezzetti, MD, G. d'Annunzio University of Chieti and the G. d'Annunzio University Foundation, Chieti, Italy; Maurizio Averna, MD, Alberto Notarbartolo, MD, University of Palermo, Palermo, Italy; Marcello Arca, MD, Anna Montali, BS, Filomena Campagna, PhD, La Sapienza University of Rome, Rome, Italy; Stefano Taddei, MD, Agostino Virdis, MD, University of Pisa, Pisa, Italy. Funding/Support: This study was supported in part by grants from the Italian Ministry of Research and Education (Center of Excellence on Aging and FIRB Project) and the Italian Ministry of Health (Progetto Finalizzato 2002)

Role of the Sponsor: All study funding was through public grants for scientific research. No funder had any role in the design and conduct of the study, in the collection, analysis, and interpretation of the data, and in the preparation, review, or approval of the manuscript. 
Acknowledgment: We are indebted to Carlo Patrono for his helpful suggestions in the design of the study and preparation of the manuscript and to Michele Scarano, Anna Maria Cupertino, Manfredi Rizzo, Antonio Castello, and Arian Frasheri for their contribution to patient recruitment and sample collection. $\mathrm{Dr}$ Cipollone dedicates this work to the memory of his mother, Ines.

\section{REFERENCES}

1. Anderson RN, Kochanek KD, Murphy SL. Report of final mortality statistics, 1995. Mon Vital Stat Rep. 1997;45(suppl 2):1-80

2. Maenber ME, Rish N, Berkman LF, Floderus B, de Faire U. Genetic susceptibility to death from coronary heart disease in a study of twins. $N$ Eng/ J Med. 1994;330:1041-1046

3. Yamada $Y$, Izawa $H$, Ichihara $S$, et al. Prediction of the risk of myocardial infarction from polymorphism in candidate genes. N Engl J Med. 2002;347:1916-1923. 4. Libby $P$, Ridker PM, Maseri A. Inflammation and atherosclerosis. Circulation. 2002:105:1135-1143. 5. van der Wal $A C$, Becker $A E$, van der Loos CM, Das PK. Site of intimal rupture or erosion of thrombosed coronary atherosclerotic plaques is characterized by an inflammatory process irrespective of the dominant plaque morphology. Circulation. 1994;89:36-44.

6. Cipollone F, Prontera C, Pini B, et al. Overexpression of functionally coupled cyclooxygenase- 2 and prostaglandin $\mathrm{E}$ synthase in symptomatic atherosclerotic plaques as a basis of prostaglandin $E(2)$ dependent plaque instability. Circulation. 2001;104: 921-927.

7. Cipollone F, Fazia $M$, lezzi A, et al. Suppression of the functionally coupled cyclooxygenase-2/PGE synthase as a basis of simvastatin-dependent plaque stabilization in humans. Circulation. 2003:107:1479. 1485.

8. Cipollone F, lezzi A, Fazia $M$, et al. The receptor RAGE as a progression factor amplifying arachidonatedependent inflammatory and proteolytic response in human atherosclerotic plaques: role of glycemic control. Circulation. 2003:108:1070-1077.

9. Cipollone F, Fazia $M$, lezzi $A$, et al. Blockade of the angiotensin II type 1 receptor stabilizes atherosclerotic plaques in humans by inhibiting PGE2 dependent matrix metalloproteinase activity. Circulation. 2004;109:1482-1488.

10. Papafili A, Hill MR, Brull DJ, et al. A common promoter variant in cyclooxygenase-2 represses gene expression: evidence for a role in the acute phase in- flammatory response. Arterioscler Thromb Vasc Biol. 2002:22:1631-1636.

11. Cipollone F, Patrono C. Cyclooxygenase-2 polymorphism: putting a brake on the inflammatory response to vascular injury? Arterioscler Thromb Vasc Biol. 2002:22:1516-1518.

12. Ridker PM, Hennekens CH, Buring JE, Rifai N. Creactive protein and other markers of inflammation in the prediction of cardiovascular disease in women. N Engl J Med. 2000;342:836-843.

13. de Vries HE, Buchner B, van Berkel TJ, Kuiper J. Specific interaction of oxidized low-density lipoprotein with macrophage-derived foam cells isolated from rabbit atherosclerotic lesions. Arterioscler Thromb Vasc Biol. 1999;19:638-645.

14. Cipollone F, lezzi A, Fazia $M$, et al. The receptor RAGE as a progression factor amplifying arachidonatedependent inflammatory and proteolytic response in human atherosclerotic plaques: role of glycemic control. Circulation. 2003:108:1070-1077.

15. Cullen L, Kelly L, Connor SO, Fitzgerald DJ. Selective cyclooxygenase-2 inhibition by nimesulide in man. I Pharmacol Exp Ther 1998:287:578-582.

16. McAdam BF, Catella-Lawson F, Mardini IA, Kapoor S, Lawson JA, FitzGerald GA. Systemic biosynthesis of prostacyclin by cyclooxygenase (COX)-2: the human pharmacology of a selective inhibitor of COX-2. Proc Natl Acad Sci U S A. 1999;96:272-277.

17. Patrono C, Pugliese F, Ciabattoni G, et al. Evidence for a direct stimulatory effect of prostacyclin on renin release in man. J Clin Invest. 1982;69:231239

18. Taddei S, Virdis A, Ghiadoni L, Magagna A, Salvetti $A$. Vitamin $C$ improves endothelium-dependent vasodilation by restoring nitric oxide activity in essential hypertension. Circulation. 1998;97:22222229

19. Hosmer DW Jr, Lemeshow S. Applied Logistic Regression. New York, NY: John Wiley; 1989

20. Zhang J, Yu KF. What's the relative risk? a method of correcting the odds ratio in cohort studies of common outcomes. JAMA. 1998;280:1690-1691.

21. Verschuren WM, Jacobs DR, Bloemberg BP, et al. Serum total cholesterol and long-term coronary heart disease mortality in different cultures: twenty-fiveyear follow-up of the Seven Countries Study. JAMA. 1995;274:131-136.

22. Libby P, Geng YJ, Aikawa M, et al. Macrophages and atherosclerotic plaque stability. Curr Opin Lipidol. 1996;7:330-335

23. De Caterina R, Cipollone F, Filardo FP, et al. LDL level reduction by 3-hydroxy-3-methyl-glutaryl co-
enzyme-A inhibitor simvastatin is accompanied by a related reduction of $\mathrm{F} 2$-isoprostane formation in hypercholesterolemic subjects: no further effect of vitamin E. Circulation. 2002;106:2543-2549.

24. Goto K, Fujii K, Onaka U, Abe I, Fujishima M. Angiotensin-converting enzyme inhibitor prevents agerelated endothelial dysfunction. Hypertension. 2000; 36:581-587.

25. Eikelboom JW, Hirsh J, Weitz J, Johnston $M, Y$ Q, Yusuf S. Aspirin-resistant thromboxane biosynthesis and the risk of myocardial infarction, stroke, or cardiovascular death in patients at high risk for cardiovascular events. Circulation. 2002;105:1650 1655.

26. Cipollone F, Patrignani $P$, Greco A, et al. Differential suppression of thromboxane biosynthesis by in dobufen and aspirin in patients with unstable angina Circulation. 1997;96:1109-1116.

27. Cipollone F, Ciabattoni G, Patrignani P, et al. Oxidant stress and aspirin-insensitive thromboxane biosynthesis in severe unstable angina. Circulation. 2000 102:1007-1013.

28. Cipollone F, Ganci A, Greco A, et al. Modulation of aspirin-insensitive eicosanoid biosynthesis by 6-methylprednisolone in unstable angina. Circulation. 2003;107:55-61.

29. Pratico D, Tillmann C, Zhang ZB, Li H, FitzGerald $\mathrm{GA}$. Acceleration of atherogenesis by COX-1 dependent prostanoid formation in low density lipoprotein receptor knockout mice. Proc Natl Acad Sci U S A. 2001:98:3358-3363.

30. Cipollone F, Rocca B, Patrono C. Cyclooxygenase expression and inhibition in atherothrombosis. Arterioscler Thromb Vasc Biol. 2004:24:246-255.

31. Topper JN, Cai J, Falb D, Gimbrone MA Jr. Identification of vascular endothelial genes differentially responsive to fluid mechanical stimuli: cyclooxygen ase-2, manganese superoxide dismutase, and endothelial cell nitric oxide sinthase are selectively upregulated by steady laminar shear stress. Proc Natl Acad Sci U S A. 1996:93:10417-10422.

32. FitzGerald GA, Patrono C. Drug therapy: the coxibs, selective inhibitors of cyclooxygenase-2. N Eng/ $\mathrm{J}$ Med. 2001;345:433-442.

33. Patrono C, Coller B, Dalen JE, et al. Plateletactive drugs: the relationships among dose, effectiveness, and side effects. Chest. 2001;119(1 suppl):39S635

34. Patrono C, Patrignani P, García Rodríguez LA. Cyclooxygenase-selective inhibition of prostanoid formation: transducing biochemical selectivity into clinical read-outs. J Clin Invest. 2001;108:7-13. 